\title{
The Effect of Including a Monetary Motive Item on the Gambling Motives Questionnaire in a Sample of Moderate Gamblers
}

\author{
Kristianne Dechant • Michael Ellery
}

Published online: 23 May 2010

(C) The Author(s) 2010. This article is published with open access at Springerlink.com

\begin{abstract}
This study explored the factor structure of the Gambling Motives Questionnaire (GMQ) with a large stratified sample of 839 moderate gamblers ( $49 \%$ female; median age category $=45-54$ years) and examined the effect of including a monetary motive item on GMQ factor structure. Participants responded to a telephone survey in which they were asked how often they gamble for each of 16 reasons, including the 15 GMQ motives and an additional motive: "to win money". Exploratory principal components analysis of the 15 GMQ items revealed three factors, together accounting for $49.04 \%$ of the total variance in GMQ scores. The factors tapped enhancement, coping and social motives, although only the coping subscale displayed strong internal consistency. A second exploratory principal components analysis of the 15 GMQ items and the monetary motive item continued to reveal three factors tapping enhancement, coping and social motives. The addition of the monetary motive item strengthened the independence of the components and dramatically improved the internal consistency of the enhancement factor. The results suggest that the psychometric properties of the GMQ, when used with a population of moderate gamblers, may be considerably strengthened with only minor modifications.
\end{abstract}

Keywords Motives · Money - Winning $\cdot$ Factor structure $\cdot$ Psychometrics

Since the 1950s, research has proposed various, sometimes conflicting, motivations for gambling, from a drive to feel alive (Kusyszyn 1990), to masochism and guilt (Bolen and Boyd 1972; Bergler 1957), and to needs for decision-making (Campbell 1976) and intellectual exercise (Herman 1976). Studies of expressed gambling motives have emphasized three motive types: gambling to increase pleasant emotions (Chevalier et al. 2002; Doley

Kristianne Dechant and Michael Ellery contributed equally to this work.

K. Dechant $(\bowtie)$

Manitoba Gaming Control Commission, 800-215 Garry Street, Winnipeg, MB R3C 3P3, Canada e-mail: kdechant@mgcc.mb.ca

M. Ellery

Department of Psychology, University of Manitoba, Winnipeg, MB, Canada 
2000; Herman 1976; Bolen and Boyd 1972; Hess and Diller 1972), gambling to reduce unpleasant emotions (Chevalier et al. 2002; Doley 2000; Scodel 1964; Tec 1964), and gambling to increase social affiliation (Chevalier et al. 2002; Doley 2000; Rosecrance 1986; Zola 1963).

These three motives are consistent with the widely-accepted three-factor model of drinking motives (Cooper et al. 1992), which labels them enhancement, coping and social motives. Given the similarities in the clinical presentations of alcohol and gambling problems (Petry 2002), it is not surprising that gambling research has largely been informed by research on alcohol. Research on gambling motives is no exception. Indeed, Stewart and Zack (2008) borrowed directly from the field of alcohol research to develop their Gambling Motives Questionnaire (GMQ), which applies the fifteen items from Cooper et al.'s (1992) Drinking Motives Questionnaire to gambling. Stewart and Zack's (2008) results revealed that the GMQ has strong psychometric properties and, like the version for alcohol, taps correlated factors for enhancement, coping and social motives.

Gambling motives studies have been criticized for using predefined lists of motives, as there is no guarantee that the most relevant motives are included (Neighbors et al. 2002). In particular, a recent critique of the GMQ (Hodgins 2008) argues that, because the items are derived from the alcohol literature, the measure fails to capture motives related to money, a limitation acknowledged by its authors (Stewart and Zack 2008). While people generally do not drink alcohol for pecuniary gain, winning money has frequently been reported among the top reasons for gambling (Hodgins 2008; Neighbors et al. 2002; Platz and Millar 2001; Wiebe et al. 2001; Doley 2000; Ladouceur and Walker 1998; Conlisk 1993; Smith and Preston 1984; Eadington 1976; Hess and Diller 1972).

A further limitation of the GMQ is that previous work to date has validated it for use only with a community-recruited sample comprised mainly of probable pathological gamblers (cf. Stewart and Zack 2008). Other gambling motives measures have been tested with gamblers more broadly, but these have been limited by their use of convenience samples of college students (Lee et al. 2006, 2007). Similar to other psychological research, on topics such as personality (Zimmerman 1994), substance use (Shedler and Block 1990), inattention (Haslam et al. 2006; Jensen 2000), social anxiety (Swinson 2005; Kendall and Ollendick 2004), sexual orientation (Lamberg 1998; Rothblum 1994) and internet use (Morahan-Martin 2005), research on gambling is at risk of pathologizing what could be normal behaviour, due, at least in part, to a currently incomplete understanding of normal gambling behaviour. Currie et al. (2006) have identified that, while gambling has become an increasingly acceptable behaviour, little research has been done on normal gambling behaviour, one of the characteristics of which is gambling no more than two to three times per month. Recognition of the limits of using alcohol research as a model for understanding gambling has resulted in a call for more research into moderate gambling (Rodgers et al. 2009). Understanding gambling motives in moderate gamblers could lead to improved educational and harm prevention initiatives.

The purposes of this study were to explore the factor structure of the GMQ with a large stratified sample of moderate gamblers from across Manitoba and to examine the effect of including a monetary motive item on its factor structure. The GMQ measure and the additional item were administered as part of a population survey with a large representative sample of past-year gamblers, and secondary analyses with a cluster of participants identified as moderate gamblers were conducted for the purposes of the current study. We hypothesized that principal components analysis of GMQ items alone would replicate the factor structure revealed in previous analyses (Stewart and Zack 2008); that is, three intercorrelated, internally-consistent factors tapping enhancement, coping and social 
motives for gambling. As it was unlikely that including a single monetary motive item would produce an entirely new factor in the GMQ, we also hypothesized that, in line with psychometric theory (Nunnally and Bernstein 1994), the addition of the item would strengthen the internal consistency of the instrument.

\section{Method}

\section{Participants}

As part of a larger study (Manitoba Gaming Control Commission 2009), quasi-randomly selected households from rural and urban communities in the province of Manitoba, Canada, were telephoned to collect data from 1,202 adult Manitobans on gambling-related attitudes, knowledge and behaviour.

Participants who reported some form of gambling in the past year were considered for inclusion in the current analysis $(n=957)$. In order to maintain consistency with previous work that included problem and non-problem players (Stewart and Zack 2008), and because gambling frequency is a useful predictor of gambling-related harms (Currie et al. 2006), confirmatory cluster analysis of gambling frequencies was used to identify a relatively homogenous subsample of moderate past-year gamblers. Hierarchical cluster analysis, using Ward's squared Euclidian distance method, was conducted on gambling frequency scores (see "Measures", below) to identify potential clusters in the sample. The agglomeration coefficients for the stages associated with one to six clusters were: $30,904,987.46 ; \quad 13,611,149.65 ; \quad 5,118,128.47 ; \quad 1,730,770.57 ; \quad 1,160,960.22 ; \quad$ and 729,572.70. When using this method, it is desirable to balance the fewest clusters with the lowest agglomeration coefficient; thus, in combination with visual analysis of the dendrogram, the results suggested four clusters. K-means cluster analysis was then conducted on the gambling frequency scores, with the solution constrained to four clusters. The cluster with the average gambling frequencies that were most in line with Currie et al.'s (2006) description of normal gamblers (i.e., those who gambled between two and three times per month) was sought. In this way, we selected a subsample representing moderate past-year gamblers who gambled 2.30 times per month, on average $(n=841)$. Average gambling frequencies for the remaining three clusters were: 351.91 times per month (i.e., almost daily gambling on all 12 behaviours measured; $n=1$ ); 67.37 times per month (i.e., approximately daily gambling on slightly more than two forms of gambling; $n=13$ ); and 21.04 times per month (i.e., some form of gambling, most days of the month; $n=102$ ). Two participants who did not complete the GMQ were excluded from further analyses.

Table 1 reports frequency counts and percentages for demographic variables, for the subsample of moderate gamblers $(n=839)$ and for the full sample $(n=1,202)$. As Table 1 indicates, the subsample was similar to the full sample across all demographic variables. Forty-nine percent $(n=409)$ of the subsample was female and the median age category endorsed was $45-54$ years. Sixty-three percent $(n=524)$ of the subsample resided in urban centres. Mean participation in all gambling activities was 27.68 $(\mathrm{SD}=29.46)$ gambling episodes per year, or more than twice per month. Participants reported gambling on an average of $3.19(\mathrm{SD}=1.95)$ different activities in the past year. While the distributions were somewhat positively skewed, the three forms of gambling most frequently reported in the past year were: buying lottery, instant win or scratch tickets $(z$ statistic for skew $=18.80 ;$ median $=3.00$ times; mean $=11.77$ times; $\mathrm{SD}=16.82)$; 
Table 1 Category ratings of sex, age, region of residence, highest education attained, employment status and household income, as percentage of subsample $(n=839)$ and sample $(n=1,202)$

\begin{tabular}{|c|c|c|c|c|}
\hline & \multicolumn{2}{|c|}{$n=839$} & \multicolumn{2}{|c|}{$n=1,202$} \\
\hline & $\%$ & $n$ & $\%$ & $n$ \\
\hline \multicolumn{5}{|l|}{ Sex } \\
\hline Women & 48.7 & 409 & 50.2 & 603 \\
\hline Men & 51.3 & 430 & 49.8 & 599 \\
\hline \multicolumn{5}{|l|}{ Age } \\
\hline 18-24 years old & 4.5 & 38 & 4.1 & 49 \\
\hline 25-34 years old & 13.8 & 116 & 12.8 & 154 \\
\hline 35-44 years old & 15.9 & 133 & 16.0 & 192 \\
\hline 45-54 years old & 22.4 & 188 & 21.4 & 257 \\
\hline $55-64$ years old & 21.7 & 182 & 22.0 & 264 \\
\hline $65-74$ years old & 10.8 & 91 & 12.8 & 154 \\
\hline 75 years and older & 8.0 & 67 & 8.6 & 103 \\
\hline Refused/don't know & 2.9 & 24 & 2.4 & 29 \\
\hline \multicolumn{5}{|l|}{ Region } \\
\hline Urban & 62.5 & 524 & 61.1 & 735 \\
\hline Rural & 37.5 & 315 & 38.9 & 467 \\
\hline \multicolumn{5}{|l|}{ Highest education attained } \\
\hline Less than high school & 9.4 & 79 & 11.3 & 136 \\
\hline Completed high school & 22.2 & 186 & 22.6 & 272 \\
\hline Some post-secondary & 16.8 & 141 & 16.7 & 201 \\
\hline Completed post-secondary & 49.1 & 412 & 47.3 & 568 \\
\hline Refused/don't know & 2.5 & 21 & 2.1 & 25 \\
\hline \multicolumn{5}{|l|}{ Employment status } \\
\hline Employed full-time & 50.7 & 425 & 47.6 & 572 \\
\hline Employed part-time & 8.7 & 73 & 8.6 & 103 \\
\hline Homemaker/unemployed/out of labour force & 7.3 & 61 & 8.9 & 107 \\
\hline Student & 2.7 & 23 & 2.8 & 34 \\
\hline Retired & 25.7 & 216 & 27.2 & 327 \\
\hline Other & 3.2 & 27 & 3.2 & 39 \\
\hline Refused/don't know & 1.6 & 14 & 1.7 & 20 \\
\hline \multicolumn{5}{|l|}{ Household income } \\
\hline Less than $\$ 20,000$ & 7.6 & 64 & 8.7 & 104 \\
\hline$\$ 20,000$ to $<\$ 30,000$ & 9.4 & 79 & 10.3 & 124 \\
\hline$\$ 30,000$ to $<\$ 50,000$ & 19.1 & 160 & 19.1 & 229 \\
\hline$\$ 50,000$ to $<\$ 80,000$ & 23.1 & 194 & 22.4 & 269 \\
\hline$\$ 80,000$ and greater & 24.1 & 202 & 21.7 & 261 \\
\hline Refused/don't know & 16.7 & 140 & 17.9 & 215 \\
\hline
\end{tabular}

buying charity raffle or fundraising tickets $(z$ statistic for skew $=54.18$; median $=3.00$ times; mean $=3.82$ times; $\mathrm{SD}=6.68)$; and playing slot machines at casinos $(z$ statistic for skew $=54.08 ;$ median $=0.00$ times; mean $=2.72$ times; $\mathrm{SD}=7.43$ ). 
Measures

The GMQ items and a monetary motive item were administered as part of a larger study on Manitobans' gambling-related attitudes, knowledge and behaviours (Manitoba Gaming Control Commission 2009). The current results were produced via secondary analyses of these data, which were not anticipated when the larger study was designed. As the larger study did not include a measure of problem or pathological gambling, the relationship between motives and gambling problems could not be examined in the current study.

\section{Gambling Frequency}

Participants were asked how often they gamble on 12 different gambling activities that are available in Manitoba. Table 2 lists these activities and presents participation counts for the subsample of moderate gamblers; for comparison, Table 3 presents participation frequencies for the full sample. Frequency of participation was rated using a 1-9 scale $(1=$ never; $2=$ less than once a year; $3=$ one to five times a year; $4=$ six to eleven times a year; $5=$ about once a month; $6=$ two or three times a month; $7=$ about once a week; $8=$ two to six times a week; $9=$ daily). In order to avoid cluster analysis of categorical variables, and because the categories would not permit more precise estimations of gambling frequency, all of the gambling frequency measures were converted to annual frequencies by using the central value for each of the nine categories. The annual frequencies were subsequently used to identify the cluster of moderate gamblers that would serve as the sample in the current study (see "Participants", above).

Table 2 Numbers of participants engaging in gambling activities, by frequency endorsed and by gambling type $(n=839)$

\begin{tabular}{|c|c|c|c|c|c|c|c|}
\hline \multirow[t]{2}{*}{ Gambling activity } & \multicolumn{7}{|c|}{ Frequency of participation } \\
\hline & Never & $\begin{array}{l}<\text { Once/ } \\
\text { year }\end{array}$ & $\begin{array}{l}1-5 / \\
\text { year }\end{array}$ & $\begin{array}{l}6-11 / \\
\text { year }\end{array}$ & $\begin{array}{l}\text { Once/ } \\
\text { month }\end{array}$ & $\begin{array}{l}2-3 / \\
\text { month }\end{array}$ & $\begin{array}{l}\text { Once/ } \\
\text { week or } \\
\text { more }\end{array}$ \\
\hline Sports lotteries or pools & 695 & 21 & 69 & 10 & 22 & 7 & 15 \\
\hline Other lottery, instant win or scratch tickets & 228 & 28 & 238 & 55 & 122 & 69 & 99 \\
\hline Charity raffle or fundraising tickets & 237 & 45 & 438 & 51 & 42 & 19 & 7 \\
\hline Bingo & 725 & 28 & 49 & 7 & 9 & 6 & 15 \\
\hline VLTs at a bar, lounge or racetrack & 605 & 42 & 131 & 16 & 20 & 16 & 9 \\
\hline Slot machines at a casino & 487 & 60 & 207 & 18 & 38 & 22 & 7 \\
\hline Table games at a casino & 742 & 27 & 59 & 3 & 3 & 4 & 1 \\
\hline Horse races, live or off-track & 725 & 39 & 70 & 3 & 0 & 1 & 1 \\
\hline $\begin{array}{l}\text { Poker for money in a bar, lounge } \\
\text { or public facility }\end{array}$ & 793 & 11 & 26 & 4 & 4 & 0 & 1 \\
\hline Poker for money at home & 648 & 33 & 104 & 18 & 22 & 8 & 6 \\
\hline $\begin{array}{l}\text { Betting money on cards or games, } \\
\text { not including poker, or on games } \\
\text { of skill such as pool, bowling or darts }\end{array}$ & 685 & 24 & 99 & 12 & 12 & 3 & 4 \\
\hline Online gambling & 825 & 3 & 7 & 1 & 0 & 2 & 1 \\
\hline
\end{tabular}


Table 3 Numbers of participants engaging in gambling activities, by frequency endorsed and by gambling type $(n=1,202)$

\begin{tabular}{|c|c|c|c|c|c|c|c|}
\hline \multirow[t]{2}{*}{ Gambling activity } & \multicolumn{7}{|c|}{ Frequency of participation } \\
\hline & Never & $\begin{array}{l}<\text { Once/ } \\
\text { year }\end{array}$ & $\begin{array}{l}1-5 / \\
\text { year }\end{array}$ & $\begin{array}{l}6-11 / \\
\text { year }\end{array}$ & $\begin{array}{l}\text { Once/ } \\
\text { month }\end{array}$ & $\begin{array}{l}2-3 / \\
\text { month }\end{array}$ & $\begin{array}{l}\text { Once/ } \\
\text { week or } \\
\text { more }\end{array}$ \\
\hline Sports lotteries or pools & 1,023 & 24 & 75 & 11 & 23 & 9 & 37 \\
\hline Other lottery, instant win or scratch tickets & 467 & 52 & 241 & 56 & 130 & 76 & 180 \\
\hline Charity raffle or fundraising tickets & 485 & 89 & 482 & 57 & 57 & 21 & 11 \\
\hline Bingo & 1,048 & 35 & 55 & 8 & 11 & 7 & 38 \\
\hline VLTs at a bar, lounge or racetrack & 904 & 50 & 150 & 18 & 29 & 20 & 31 \\
\hline Slot machines at a casino & 762 & 77 & 230 & 22 & 47 & 30 & 34 \\
\hline Table games at a casino & 1,076 & 31 & 75 & 4 & 4 & 9 & 3 \\
\hline Horse races, live or off-track & 1,065 & 51 & 79 & 3 & 1 & 1 & 2 \\
\hline $\begin{array}{l}\text { Poker for money in a bar, } \\
\text { lounge or public facility }\end{array}$ & 1,135 & 15 & 30 & 5 & 8 & 1 & 8 \\
\hline Poker for money at home & 965 & 40 & 122 & 22 & 28 & 11 & 14 \\
\hline $\begin{array}{l}\text { Betting money on cards or games, } \\
\text { not including poker, or on games } \\
\text { of skill such as pool, bowling or darts }\end{array}$ & 1,018 & 34 & 109 & 13 & 13 & 5 & 10 \\
\hline Online gambling & 1,176 & 5 & 9 & 1 & 1 & 3 & 7 \\
\hline
\end{tabular}

\section{Gambling Motives}

Participants were asked how often they gamble for each of 16 reasons. Fifteen of the items (listed in Table 4) constitute the GMQ, which asks respondents to rate the relative frequency of different motives using a scale from 1 to 4 ( 1 = never or almost never; $2=$ sometimes; $3=$ often; $4=$ almost always or always). The sixteenth item, "to win money", was answered using the same scale. The motive items were rotated in the telephone interview to ensure that participants were not influenced by the order of presentation of the questions.

\section{Demographics}

Age, sex, household income, region of residence, educational attainment and employment status data were measured as categorical variables.

\section{Procedure}

A professional research company interviewed participants via telephone in January 2009. To ensure that all Manitoba households with a landline had an equal chance of being included, a geographically-representative random sample was drawn from all listed telephone numbers in the province and included computer-generated numbers to account for unlisted numbers. Quotas were established to ensure accurate representation by sex and region.

The telephone surveys, which took approximately $15 \mathrm{~min}$, were conducted by trained interviewers, who advised participants of study procedures and confidentiality prior to 
Table 4 Pattern matrix of the 15-item GMQ

$\begin{array}{llll}\text { Factor 1: } & \text { Factor } & \text { Factor } & \text { Communality } \\ \text { enhancement } & 2: & 3: & \\ & \text { coping } & \text { social } & \\ & & & \end{array}$

Enhancement motives subscale

... because you like the feeling?

$\mathbf{0 . 8 1 7} \quad-0.024 \quad-0.031 \quad 0.642$

... because it's exciting?

$\begin{array}{lllll}\mathbf{0 . 7 2 8} & -0.082 & 0.142 & 0.592\end{array}$

... because it makes you feel good?

$\begin{array}{lllll}\mathbf{0 . 7 2 4} & 0.143 & 0.055 & 0.634\end{array}$

... because it's fun?

$\begin{array}{lllll}\mathbf{0 . 6 3 2} & -0.211 & 0.302 & 0.577\end{array}$

... to get a 'high' feeling?

0.605

$\begin{array}{lll}0.170 & -0.184 & 0.398\end{array}$

Coping motives subscale

... to forget your worries?

$\begin{array}{llll}0.121 & \mathbf{0 . 7 6 9} & -0.092 & 0.637\end{array}$

... because it helps when you are feeling nervous or

0.023

$\mathbf{0 . 7 2 7}-0.127 \quad 0.525$ depressed?

... to cheer you up when you're in a bad mood?

$\begin{array}{rrrr}0.017 & \mathbf{0 . 6 4 3} & 0.082 & 0.442 \\ -0.018 & \mathbf{0 . 4 8 4} & 0.154 & 0.273\end{array}$
yourself?

... to relax?

$\begin{array}{llll}\mathbf{0 . 3 8 0} & 0.280 & 0.145 & 0.351\end{array}$

Social motives subscale

$\ldots$ to be sociable?

\author{
0.102
}

$\begin{array}{lll}-0.119 & \mathbf{0 . 7 2 6} & 0.572\end{array}$

... because it's what most of your friends do when they get -0.101

$\begin{array}{lll}0.039 & \mathbf{0 . 7 0 7} & 0.468\end{array}$ together?

... because it makes a social gathering more enjoyable?

0.130
-0.044
0.102

$\begin{array}{lll}0.008 & \mathbf{0 . 6 8 7} & 0.553\end{array}$

$\ldots$ as a way to celebrate?

$\mathbf{0 . 3 5 3} \mathbf{0 . 5 1 2} 0.417$

... it's something you do on special occasions?

0.102

$\begin{array}{lll}0.007 & \mathbf{0 . 4 8 0} & 0.276\end{array}$

The first five eigenvalues were as follows: $4.27,1.81,1.28,0.96$, and 0.88 . Salient factor loadings $(\geq 0.32)$ are in bold font

acquiring verbal consent to participate in the anonymous survey. Participants did not receive compensation for taking part in the survey.

\title{
Analysis
}

Two principal components analyses were conducted on the item responses of the cluster of moderate gamblers $(n=839)$. The first was to explore the factor structure of the GMQ in this sample. The second examined the effect of including a monetary motive item in the GMQ on its factor structure in this sample.

\section{Results}

Mahalanobis distance calculations suggested the possible presence of multivariate outliers. However, the recommended practice of systematically excluding cases on the basis of Mahalanobis distances eventually resulted in a sample that lacked sufficiently variability to conduct principal components analyses (Tabachnick and Fidell 2007). Concerns that these cases might unduly influence the analysis were mitigated by the large sample size and by the fact that Mahalanobis distance calculations consistently overestimate the presence of 
multivariate outliers (Tabachnick and Fidell 2007). All 839 cases in the moderate gambling cluster were retained to ensure sufficient variability in item scores to analyze the factor structure of the GMQ in this behaviourally homogenous cluster (in terms of gambling frequency). Missing values for the GMQ items (less than $0.5 \%$ of the dataset) were replaced with item means.

Factor Structure of the 15-Item GMQ

Due to the expected intercorrelation of the GMQ scales, an exploratory examination of the factor structure of the 15 GMQ items was conducted using principal components analysis with oblimin rotation. The Kaiser-Meyer-Olkin statistic of 0.84 suggested that the sample was adequate. The chi-square statistic for Bartlett's test of sphericity was estimated at 3055.79 , df $=105, P<0.000$, indicating that the data reduction was warranted.

Visual examination of the scree plot and parallel analysis (O'Connor 2000) both indicated that three components should be retained. The three components, corresponding to enhancement, coping and social motives, accounted for $49.04 \%$ of the total variance in GMQ scores. The first component accounted for $28.49 \%$, the second accounted for $12.05 \%$, and the third accounted for $8.50 \%$.

Table 4 displays the pattern matrix, with items grouped based on Stewart and Zack's (2008) GMQ subscales. The pattern matrix was interpreted with component loadings greater than 0.32 considered salient (Tabachnick and Fidell 2007). Applying Thurstone's (1947) criteria, the absence of hyperplane items and the magnitude of the salient loadings contributed to the strength of the factor structure of the GMQ. However, the simple structure was compromised by the complex loading of one item, "as a way to celebrate", on both the coping and social factors. Also, in this sample, "to relax" loaded unexpectedly on the enhancement factor, rather than on the coping factor.

The components were correlated, as expected, supporting the obliquely-rotated solution. Table 5 presents the component correlation matrix, internal consistencies, and descriptive statistics for the subscales.

Factor Structure of the 15-Item GMQ plus the Monetary Motive Item

A second exploratory principal components analysis was conducted to evaluate the effect of adding the monetary motive item. Oblimin rotation was again used, because of the expected intercorrelation of the GMQ scales. The mean score of the monetary motive item was 1.94 ( $\mathrm{SD}=1.18$ ). The Kaiser-Meyer-Olkin statistic of 0.84 suggested that the sample was adequate and the chi-square statistic for Bartlett's test of sphericity was estimated at $3193.48, \mathrm{df}=120, P<0.000$, indicating that analysis was warranted.

Table 5 Descriptive statistics, internal consistencies and intercorrelations for the factors of the 15-item GMQ

\begin{tabular}{llllll}
\hline & Mean & SD & Cronbach's alpha & \multicolumn{2}{l}{ Factor intercorrelations } \\
\cline { 5 - 6 } & & & & 1 & 2 \\
\hline Factor 1: enhancement & 7.49 & 2.91 & 0.57 & - & - \\
Factor 2: coping & 5.59 & 1.34 & 0.76 & 0.271 & - \\
Factor 3: social & 7.02 & 2.37 & 0.67 & $\mathbf{0 . 3 4 8}$ & 0.145 \\
\hline
\end{tabular}

Salient intercorrelations $(\geq 0.32)$ are in bold font 
As in the previous analysis, visual examination of the scree plot and parallel analysis (O'Connor 2000) were used to determine the number of components to retain. The results of the analysis with the monetary motive item continued to suggest a three-factor solution, the three components of which tapped social, coping and enhancement motives and accounted for $47.21 \%$ of the total variance. The first component accounted for $27.30 \%$, the second component for $11.31 \%$, and the third for $8.60 \%$. Unexpectedly, the components shared less than $10 \%$ of the variance; however, due to the a priori hypothesis that the components would be intercorrelated, and because the components of the 15-item GMQ were intercorrelated in this same sample, the pattern matrix resulting from the obliminrotated analysis was interpreted. Item loadings greater than 0.32 were considered salient (Tabachnick and Fidell 2007). Table 6 displays the pattern matrix for the 16-item analysis and Table 7 presents the descriptive statistics and internal consistencies of the components.

The GMQ items in this analysis loaded primarily onto the theoretically expected subscales. With respect to Thurstone's (1947) criteria, the absence of hyperplane items and the magnitude of the salient loadings attested to the strength of the factor structure of the 16 items in this sample. However, the simple structure was compromised by two complex loadings: "as a way to celebrate" loaded on both the coping and social factors and "because it's fun" loaded on both the social and enhancement factors. The monetary

Table 6 Pattern matrix of the 15-item GMQ plus the monetary motive item

\begin{tabular}{|c|c|c|c|c|}
\hline & $\begin{array}{l}\text { Factor 1: } \\
\text { enhancement }\end{array}$ & $\begin{array}{l}\text { Factor 2: } \\
\text { coping }\end{array}$ & $\begin{array}{l}\text { Factor 3: } \\
\text { social }\end{array}$ & Communality \\
\hline \multicolumn{5}{|l|}{ Enhancement motives subscale } \\
\hline ... because you like the feeling? & -0.729 & 0.039 & 0.087 & 0.593 \\
\hline ... because it's exciting? & -0.713 & -0.049 & 0.203 & 0.614 \\
\hline$\ldots$ to win money? & -0.647 & -0.044 & -0.211 & 0.375 \\
\hline ... because it's fun? & -0.612 & -0.184 & 0.363 & 0.587 \\
\hline ... because it makes you feel good? & -0.600 & 0.213 & 0.180 & 0.580 \\
\hline ... to get a 'high' feeling? & $-\mathbf{0 . 5 2 2}$ & 0.224 & -0.093 & 0.356 \\
\hline \multicolumn{5}{|l|}{ Coping motives subscale } \\
\hline$\ldots$ to forget your worries? & -0.085 & 0.787 & -0.099 & 0.636 \\
\hline $\begin{array}{l}\ldots \text { because it helps when you are feeling nervous } \\
\text { or depressed? }\end{array}$ & 0.014 & 0.742 & -0.137 & 0.527 \\
\hline ... to cheer you up when you're in a bad mood? & -0.010 & 0.643 & 0.051 & 0.432 \\
\hline $\begin{array}{l}\text {... because you feel more self-confident or sure } \\
\text { of yourself? }\end{array}$ & 0.019 & 0.481 & 0.124 & 0.263 \\
\hline$\ldots$ to relax? & -0.271 & 0.330 & 0.228 & 0.344 \\
\hline \multicolumn{5}{|l|}{ Social motives subscale } \\
\hline$\ldots$ to be sociable? & -0.034 & -0.103 & 0.772 & 0.592 \\
\hline $\begin{array}{l}\text {... because it makes a social gathering more } \\
\text { enjoyable? }\end{array}$ & -0.073 & 0.021 & 0.721 & 0.562 \\
\hline $\begin{array}{l}\text {... because it's what most of your friends do } \\
\text { when they get together? }\end{array}$ & 0.119 & 0.031 & 0.698 & 0.460 \\
\hline ... as a way to celebrate? & 0.022 & $\mathbf{0 . 3 3 4}$ & 0.463 & 0.374 \\
\hline ... it's something you do on special occasions? & -0.133 & -0.009 & 0.453 & 0.256 \\
\hline
\end{tabular}

The first five eigenvalues were as follows: 4.37, 1.81, 1.38, 1.00, and 0.88. Salient factor loadings ( $\geq 0.32)$ are in bold font 
Table 7 Descriptive statistics, internal consistencies and intercorrelations for the factors of the 15-item GMQ plus the monetary motive item

\begin{tabular}{llllll}
\hline & Mean & SD & Cronbach's alpha & \multicolumn{2}{l}{ Factor intercorrelations } \\
\cline { 4 - 5 } & & & & 1 & 2 \\
\hline Factor 1: enhancement & 9.43 & 3.49 & 0.74 & - & - \\
Factor 2: coping & 5.59 & 1.34 & 0.76 & -0.257 & - \\
Factor 3: social & 7.02 & 2.37 & 0.67 & -0.290 & 0.186 \\
\hline
\end{tabular}

Note: The monetary motive item score is included in the enhancement factor

There were no salient intercorrelations $(\geq 0.32)$

motive item, "to win money", loaded onto the enhancement factor. As expected, the addition of the monetary motive item strengthened both the independence of the components and the internal consistency of the enhancement factor (increasing Cronbach's alpha from 0.57 to 0.74 ).

\section{Discussion}

Principal components analysis of the 15 GMQ items revealed three factors tapping enhancement, coping and social motives, as hypothesized based on previous analyses (Stewart and Zack 2008). However, only the enhancement and social subscales showed a salient intercorrelation, possibly due to the sample composition. Relative to previous studies (Stewart and Zack 2008), the sample of moderate gamblers in the current study was likely comprised of fewer problem and pathological gamblers (Rodgers et al. 2009), resulting in less variability in the item endorsements. In analysis of the 15 GMQ items, the coping subscale displayed strong internal consistency, but the social and enhancement subscales were notably weaker and, in fact, below the suggested minimum standard of 0.70 for research instruments (Nunnally and Bernstein 1994). This suggests that the 15-item GMQ may be inappropriate for use in large population surveys.

The 15-item GMQ displayed acceptable simple structure. Fourteen items displayed salient loadings onto their expected subscales. As in previous research (Stewart and Zack 2008), the items that loaded most saliently onto the coping and social subscales were, respectively, "to forget worries" and "to be sociable". The item that loaded most saliently on the enhancement subscale was "because you like the feeling", which has high face validity.

One item, "to relax", loaded only onto enhancement, though it loaded most saliently onto the coping subscale in previous research (Stewart and Zack 2008). In Stewart and Zack (2008), this item had loaded on both the enhancement and coping subscales, suggesting to the authors that relaxation has different meanings for enhancement and coping gamblers. Consistent with this interpretation, the moderate gamblers in the current sample may have been more likely to engage in gambling for leisure than to reduce anxiety. Stewart and Zack (2008) also found that "because you feel more self-confident or sure of yourself" loaded onto both the social and coping subscales. As theoretically expected, this item loaded only on the coping subscale in the current study. Unlike the previous study (Stewart and Zack 2008), "to celebrate" loaded unexpectedly onto two subscales: social and coping. Although theoretically this item should have loaded only onto the social 
subscale, it may be that coping gamblers in this study gambled to reduce unpleasant emotions associated with social pressure to gamble that they may experience when celebrating with others.

Principal components analysis of the 15-item GMQ plus the monetary motive item continued to reveal a three-factor solution tapping enhancement, coping and social motives. As predicted, the addition of the monetary motive strengthened the independence of the factors. None of the three subscales showed salient intercorrelation, resulting in an essentially orthogonal, and thus improved, solution.

The monetary motive item loaded strongly on the enhancement subscale. This is preliminary evidence that moderate gamblers may think of winning money as a way to increase pleasant emotion, rather than as a way to increase social affiliation or to cope with unpleasant emotion. Including the monetary motive item on the enhancement subscale dramatically improved the subscale's internal consistency, from a Cronbach's alpha of 0.57 to 0.74 . While the social motives subscale remains weaker in terms of its internal consistency (Cronbach's alpha of 0.67), the improvement made by adding the monetary motive item to the enhancement subscale, along with the strength of the coping subscale (Cronbach's alpha of 0.76), suggests that the inclusion of more monetary motive items could further improve the internal consistency of the GMQ subscales when used with the general population.

Adding the monetary motive item also improved the simple structure of the three-factor solution in this sample of moderate gamblers. Although "as a way to celebrate" continued to load on the social and coping subscales, it loaded less saliently onto the coping subscale. Instead of loading onto the enhancement subscale as it did in the 15-item measure, adding the monetary motive item resulted in "to relax" loading only onto the coping subscale, as theoretically expected. However, this also resulted in a complex loading for "because it's fun" onto both the enhancement and social subscales. This may be due to the increased internal consistency of the enhancement subscale. That is, with enhancement more narrowly defined, the "because it's fun" item appears to better tap affiliation (i.e., gambling to increase positive external reinforcement) in this sample.

The impact on factor structure of adding the monetary motive item to the GMQ supports the critique (Hodgins 2008) that failing to capture motives related to money was a significant omission in the initial GMQ development. One limitation of this study is that only one monetary item was available in the larger study to be included in these secondary analyses. Actually, gambling could be motivated by a number of financial reasons. Though studies (Chevalier et al. 2002; Neighbors et al. 2002) have found winning money to be a primary motive, one study (Hodgins 2008) pointed out that it may be the possibility of winning money, rather than actual monetary gain that is the reason people gamble. This is consistent with studies of brain physiology. For instance, researchers have observed activation in the ventral striatum in anticipation of a monetary reward (Knutson et al. 2001). Moreover, dopamine release has been observed to increase immediately prior to an expected reward (Breiter et al. 2001). People could also be motivated by the idea of winning money because this represents the possibility of a major change in prestige or lifestyle (Smith and Preston 1984; Eadington 1976; Hess and Diller 1972; Zola 1963). There is also some evidence to suggest that some people believe it is more lucrative to gamble than to invest in short-term or low-interest investments (Chevalier et al. 2002), and so may be motivated to use gambling as a financial tool.

In developing their Gambling Expectancy Questionnaire with an adolescent sample, Gillespie et al. (2007) found that money emerged as a distinct factor from the other positive 
outcome expectancies (i.e., enjoyment/arousal and self-enhancement). Though the constructs of expectancies and motives are not identical, they can be expected to overlap. Gillespie et al.'s (2007) results suggest the possibility that a greater number of monetary motive items could lead to the emergence of a separate factor in future studies. Therefore, future research should incorporate additional monetary motive items to explore whether they would continue to load onto the enhancement-or other-subscales, or whether a distinct factor would emerge. Psychometric theory suggests that a minimum number of items to include in an exploratory analysis ought to exceed five or six items, as factors with fewer than five strongly loading items would likely be weak and unreliable (Tabachnick and Fidell 2007; Costello and Osborne 2005). Future research could also examine how different gambling motives, including monetary motives, predict different levels of gambling involvement.

In addition to providing preliminary evidence that the GMQ might benefit from the addition of monetary items, the results suggest that the GMQ may be suitable for telephone administration in research with moderate gamblers. As the current study is the first, to the authors' knowledge, to use the GMQ to analyze moderate gamblers' motives, further use of the measure with this population is warranted, and would be timely given calls for more research along the spectrum of gambling behaviours (Rodgers et al. 2009). Future research could also examine the effects of different motive types on the gambling behaviour of demographic subsets of moderate gamblers. For example, preliminary evidence suggests that older adults may be less motivated than younger adults by the possibility of winning money, but that they may gamble more frequently for social or affective motives (Clarke 2008; Southwell et al. 2008).

The use of self-report items is another limitation of this study. Self-report studies assume that gamblers are capable of and willing to accurately report their motives for gambling. Future research could consider laboratory-based studies of directly observed gambling behaviours as a means to investigate the construct validity of the GMQ subscales. Future research might also consider the inclusion of a measure of problem or pathological gambling to directly examine gambling motives as vulnerabilities to the incidence of gambling problems in a moderate gambling population.

Another important limitation is the presence of multivariate outliers in the moderate gambling cluster. Although it was necessary in this study to retain the data of all gamblers in this cluster to ensure sufficient variability in item scores to conduct the analysis, the presence of multivariate outliers indicates the results should be interpreted cautiously. Additional research on the impact of adding monetary motive items is required before recommending a modified GMQ for widespread use.

While the GMQ has been criticized for its use of items borrowed directly from a measure developed to understand motives for problematic alcohol use, the results of the current study demonstrate that the psychometric properties of the GMQ may be considerably strengthened with only minor modifications.

Acknowledgements The authors are grateful to Luisa Pontanares for her assistance with the literature review.

Open Access This article is distributed under the terms of the Creative Commons Attribution Noncommercial License which permits any noncommercial use, distribution, and reproduction in any medium, provided the original author(s) and source are credited. 


\section{References}

Bergler, E. (1957). The psychology of gambling. New York: Hill and Wang.

Bolen, D. W., \& Boyd, W. (1972). Gambling and the gambler: A review and preliminary findings. In I. Kusyszyn (Ed.), Studies in the psychology of gambling (pp. 11-27). New York: Simon \& Schuster.

Breiter, H. C., Aharon, I., Kahneman, D., Dale, A., \& Shizgal, P. (2001). Functional imaging of neural responses to expectancy and experience of monetary gains and losses. Neuron, 30, 619-639.

Campbell, F. (1976). Gambling: A positive view. In W. R. Eadington (Ed.), Gambling in society: Interdisciplinary studies on the subject of gambling (pp. 218-228). Springfield, IL: Charles C. Thomas.

Chevalier, S., Geoffrion, C., Allard, D., \& Audet, C. (2002). Motivations for gambling as tools for prevention and treatment of pathological gambling. Québec: Institut national de santé publique du Québec.

Clarke, D. (2008). Older adults' gambling motivation and problem gambling: A comparative study. Journal of Gambling Studies, 24(2), 175-192.

Conlisk, J. (1993). The utility of gambling. Journal of Risk and Uncertainty, 6(3), 255-275.

Cooper, M. L., Russell, M., Skinner, J. B., \& Windle, M. (1992). Development and validation of a threedimensional measure of drinking motives. Psychological Assessment, 4(2), 123-132.

Costello, A. B., \& Osborne, J. W. (2005). Best practices in exploratory factor analysis: Four recommendations for getting the most from your analysis. Practical Assessment, Research \& Evaluation, 10(7), $1-9$.

Currie, S. R., Hodgins, D. C., Wang, J., el-Guebaly, N., Wynne, H., \& Chen, S. (2006). Risk of harm among gamblers in the general population as a function of level of participation in gambling activities. Addiction, 101, 570-580.

Doley, R. (2000). Want to make a bet? Gambling and crime in Australasia. Paper Series No. 4. Payneham, SA: Australasian Centre for Policing Research.

Eadington, W. R. (1976). Economic aspects of Nevada's gaming industry. In W. R. Eadington (Ed.), Gambling and society: Interdisciplinary studies on the subject of gambling (pp. 138-158). Springfield, IL: Charles C. Thomas.

Gillespie, M. A. M., Derevensky, J., \& Gupta, R. (2007). Adolescent problem gambling: Developing a gambling expectancy instrument. Journal of Gambling Issues, 19, 51-68.

Haslam, N., Williams, B., Prior, M., Haslam, R., Graetz, B., \& Sawyer, M. (2006). The latent structure of attention-deficit/hyperactivity disorder: A taxometric analysis. Australian and New Zealand Journal of Psychiatry, 40, 639-647.

Herman, R. D. (1976). Motivations to gamble: The model of Roger Callois. In W. R. Eadington (Ed.), Gambling and society: Interdisciplinary studies on the subject of gambling (pp. 207-217). Springfield, IL: Charles C. Thomas.

Hess, H. F., \& Diller, J. V. (1972). Motivation for gambling as revealed in the marketing methods of the legitimate gambling industry. In I. Kusyszyn (Ed.), Studies in the psychology of gambling (pp. 81-92). New York: Simon \& Schuster.

Hodgins, D. C. (2008). What we see depends mainly on what we look for (commentary). Addiction, 103, $1118-1119$.

Jensen, P. S. (2000). Commentary: The NIH ADHD consensus statement: Win, lose, or draw? Journal of the American Academy of Child and Adolescent Psychiatry, 39, 194-197.

Kendall, P. C., \& Ollendick, T. H. (2004). Setting the research and practice agenda for anxiety in children and adolescence: A topic comes of age. Cognitive and Behavioral Practice, 11, 65-74.

Knutson, B., Fong, G. W., Adams, C. M., Varner, J. L., \& Hommer, D. (2001). Dissociation of reward anticipation and outcome with event-related fMRI. NeuroReport, 12, 3683-3687.

Kusyszyn, I. (1990). Existence, effectance, esteem: From gambling to a new theory of human motivation. Substance Use and Misuse, 25(2), 159-177.

Ladouceur, R., \& Walker, M. (1998). The cognitive approach to understanding and treating pathological gambling. In A. S. Bellack \& M. Hersen (Eds.), Comprehensive clinical psychology (pp. 588-601). New York: Pergamon.

Lamberg, L. (1998). Gay is okay with APA—forum honors landmark 1973 events. Journal of the American Medical Association, 280, 497-499.

Lee, H., Chae, P. K., Lee, H., \& Kim, Y. (2007). The five-factor gambling motivation model. Psychiatry Research, 150, 21-32.

Lee, C., Lee, Y., Bernhard, B. J., \& Yoon, Y. (2006). Segmenting casino gamblers by motivation: A cluster analysis of Korean gamblers. Tourism Management, 27, 856-866.

Manitoba Gaming Control Commission. (2009). Limit-setting campaign evaluation report. Manitoba: Winnipeg. 
Morahan-Martin, J. (2005). Internet abuse: Addiction? Disorder? Symptom? Alternative Explanations? Social Science Computer Review, 23, 39-48.

Neighbors, C., Lostutter, T. W., Cronce, J. M., \& Larimer, M. E. (2002). Exploring college student gambling motivation. Journal of Gambling Studies, 18(4), 361-370.

Nunnally, J. C., \& Bernstein, I. H. (1994). Psychometric theory (3rd ed.). New York: McGraw-Hill.

O'Connor, B. P. (2000). SPSS and SAS programs for determining the number of components using parallel analysis and Velicer's MAP test. Behavior Research Methods, Instruments \& Computers, 32(3), 396402.

Petry, N. M. (2002). How treatments for pathological gambling can be informed by treatments for substance use disorders. Psychopharmachology, 10, 184-192.

Platz, L., \& Millar, M. (2001). Gambling in the context of other recreation activity: A quantitative comparison of casual and pathological student gamblers. Journal of Leisure Research, 33(4), 383-395.

Rodgers, B., Caldwell, T., \& Butterworth, P. (2009). Measuring gambling participation. Addiction, 104, 1065-1069.

Rosecrance, J. (1986). Why regular gamblers don't quit: A sociological perspective. Sociological Perspectives, 29(3), 357-378.

Rothblum, E. D. (1994). "I only read about myself on bathroom walls": The need for research on the mental health of lesbians and gay men. Journal of Consulting and Clinical Psychology, 62, 213-220.

Scodel, A. (1964). Inspirational group therapy: A study of gambler's anonymous. American Journal of Psychotherapy, 18, 115.

Shedler, J., \& Block, J. (1990). Adolescent drug use and psychological health: A longitudinal inquiry. American Psychologist, 45, 612-630.

Smith, R. W., \& Preston, F. W. (1984). Vocabularies of motives for gambling behavior. Sociological Perspectives, 27(3), 325-348.

Southwell, J., Boreham, P., \& Laffan, W. (2008). Problem gambling and the circumstances facing older people: A study of gaming machine players aged $60+$ in licensed clubs. Journal of Gambling Studies, 24(2), 151-174.

Stewart, S. H., \& Zack, M. (2008). Development and psychometric evaluation of a three-dimensional gambling motives questionnaire. Addiction, 103, 1110-1117.

Swinson, R. P. (2005). Social anxiety disorder. The Canadian Journal of Psychiatry, 50, 305-307.

Tabachnick, B. G., \& Fidell, L. S. (2007). Using multivariate statistics (5th ed.). Boston, MA: Pearson Education Inc.

Tec, N. (1964). Gambling in Sweden. Totowa, NJ: Bedminster Press.

Thurstone, L. L. (1947). Multiple factor analysis. Chicago, IL: University of Chicago Press.

Wiebe, J., Single, E., \& Falkowski-Ham, A. (2001). Measuring gambling and problem gambling in Ontario. Report prepared for the Canadian Centre on Substance Abuse and Responsible Gambling Council (Ontario).

Zimmerman, M. (1994). Diagnosing personality disorders: A review of issues and research methods. Archives of General Psychiatry, 51, 225-245.

Zola, I. (1963). Observations on gambling in a lower-class setting. Social Problems, 10(4), 353-361. 